\title{
Prevalence of smoking during pregnancy in the Republic of the Congo: Maternal smoking is associated with increased risk of prenatal alcohol exposure
}

\author{
Andrew D. Williams ${ }^{1}$, Yannick Nkombo ${ }^{2}$, Gery Nkodia ${ }^{2}$, Gary Leonardson ${ }^{3}$, and Larry Burd ${ }^{1}$ \\ ${ }^{1}$ North Dakota Fetal Alcohol Syndrome Center, University of North Dakota, Grand Forks, ND, U.S.A. \\ ${ }^{2}$ Congolese Association for Research and Prevention of Fetal Alcohol Spectrum Disorders, Brazzaville, Congo \\ ${ }^{3}$ Mountain Plains Research, Dillon, MT, U.S.A.
}

\begin{abstract}
Aims: Development of useful estimates of rates of maternal smoking during pregnancy, and the impact of smoking on rates and duration of maternal alcohol use during pregnancy.

Design: A prospective study utilizing systematic screening of consecutive pregnant women.

Setting: Ten prenatal care sites in Brazzaville, Congo's largest city, where 50\% of live births in the Congo occur. Women were asked to report the number of cigarettes smoked per day.

Findings: From the 10 sites, 3,099 women were screened and 5.5\% $(n=172)$ reported smoking. The mean number of cigarettes smoked per day was 1.1 and only $11 \%(n=19)$ of the women reported smoking two or more cigarettes per day during pregnancy. Smoking during pregnancy was associated with a 4.9-fold increase in prenatal alcohol exposure during pregnancy. We found that $93 \%$ of the women who smoked also used alcohol during pregnancy.

Conclusions: While the prevalence of smoking and the average number of cigarettes smoked per day were both low, smoking at any level results in a huge increase in risk for maternal alcohol use during pregnancy. The trend across the developing world is for increasing rates of smoking among women and children. Since the number of cigarettes smoked per day was low, smoking cessation programs and public health warnings may be useful in further reducing rates of smoking during pregnancy and, thus, risk for prenatal alcohol exposure in the Congo. We believe this is the first report quantifying the risk of smoking and prenatal alcohol use in a population of pregnant women.
\end{abstract}

In developing countries, funding for public health efforts is severely limited. Accurate prevalence data from individual countries is required to establish a need for intervention efforts which may share in the allocation of scarce public health prevention funding.

Developing countries account for over $70 \%$ of worldwide tobacco use (Doskotch, 2008). The impact of smoking in the developing world is illustrated by reports that lowincome households in Egypt spend more than $10 \%$ of household expenditures on tobacco, homeless people in India spend more on tobacco than food, and in some areas of China, smokers spend more than $60 \%$ of personal income and $17 \%$ of total household income on cigarettes (Jagoe, Edwards, Mugusi, Whiting, \& Unwin, 2002).

While women comprise only $9 \%$ of smokers in the developing world, there are signs that this number could rapidly increase in response to marketing efforts by tobacco companies focused on women and children in the developing world (Ernster, Kaufman, Nichter, Samet, \& Yoon, 2000; Geirsson \& Tolosa, 2010; Mackay, Eriksen, \& Shafey, 2006). This has led to increased concern about the adverse effects of tobacco use during pregnancy (Anderka et al., 2010). Maternal smoking has been found to be a marker for large increases in risk for multiple adverse outcomes, including fetal mortality, stillbirth, infant and child mortality, preterm birth and morbidity (Cnattingius, 2004; England et al., 2010). While a review of the link between maternal smoking and adverse events during pregnancy is beyond the scope of this paper, maternal smoking is a huge risk factor for maternal and child health worldwide (Cnattingius, 2004).

Each year, approximately 167 million babies are born in Sub-Saharan Africa. Multiple risk factors are pervasive in these countries, including poor nutrition, lack of clean water, poor sanitation, and access to medical care; these 
contribute to high rates of prematurity and high maternal and infant mortality rates (United Nations, 2010). Research on maternal smoking during pregnancy in Sub-Saharan Africa has been limited to only a few countries. As demonstrated in Table 1, rates of maternal smoking in SubSaharan Africa vary 200 -fold, from $0.2 \%$ in Zambia and the Democratic Republic of the Congo to $45.6 \%$ in South Africa (Chaibva, Ehlers, \& Roos, 2011; Croxford \& Viljoen, 1999; Fourn, Ducic, \& Seguin, 1999; Kadir et al., 2010; McDermott, Steketee, Larsen, \& Wirima, 1993; Namagembe et al., 2010).

Research on public health issues in the Congo and information available to the government about pregnancyassociated risks has been limited. Available maternal-child health risk indicators identify the Congo as one of the poorest countries in the world. The Congo has a per capita income of $\$ 3,732$, and annual per capita health expenditure is only $\$ 108$, which ranks 145 th worldwide for per capita health expenditures (U.S. Department of State, 2012; World Health Organization, 2011). One in six infants $(16.7 \%)$ born in the Congo are delivered prematurely, which is the second-highest rate in the world (Partnership for Maternal, Newborn, \& Child Health, 2012). The maternal mortality ratio is the 19th-highest rate in the world, at 580 per 100,000 (World Health Organization, 2010). The infant mortality rate is 74.2 per 1,000 live births, and is the 17th highest in the world (Central Intelligence Agency, 2012).

These factors have resulted in a suboptimal environment for pregnant women, mothers, infants, and children. Prior to this project, there had been no known published reports of population-based screening for maternal smoking during pregnancy in the Congo.

\section{Methods}

These data are part of a larger ongoing prospective study of prenatal risk markers, including prenatal alcohol exposure, in the Congo. Data collection was completed at 10 prenatal care sites in Brazzaville. The Congo has a high birth rate
(36 births per 1,000 people), and the city of Brazzaville has 50,000 live births annually (Population Reference Bureau, 2012). The prenatal care staff selected 10 prenatal care sites in Brazzaville that were thought to be representative of prenatal care in the city, based upon the number of women attending at each site, available clinic space, and location.

Ongoing consultation via phone was provided for the prenatal care staff during training and the data collection period. Each participant was interviewed in French or a local language. Data were collected for the following variables: estimated week of gestation at the time of the screening, maternal age, maternal weight at the time of the screening, and number of cigarettes smoked per day. The sites screened 3,099 women at the 10 sites from December 2011 to March 2012.

The smoking data were self-reported by participants. We did not collect data on other tobacco exposure. The data for each subject were reviewed for errors. Any out-ofrange values were reconciled by e-mail or phone with the prenatal care chart. Since smoking and alcohol use commonly co-occur during pregnancy, we also used data from a companion study of prenatal alcohol exposure to calculate smoking rates among women who never drank during pregnancy, women who drank but quit at recognition of pregnancy, and those who continued to drink after recognition of pregnancy (Cannon, Dominique, O’Leary, Sniezek, \& Floyd, 2012; Meschke, Holl, \& Messelt, 2012).

\section{Ethics Approval}

We obtained approval for the study from the University of North Dakota Institutional Review Board, Grand Forks, ND; SAF Congo, Brazzaville, Congo; and the Ministry of Health, Brazzaville, Congo. The consent forms were in French, and each consenting participant provided written consent and received a copy of the form to keep.

\section{Table 1}

A summary of the published papers including descriptive data and reported prenatal smoking rates from Sub-Saharan Africa. Only studies reporting data collected during pregnancy were included.

\begin{tabular}{|c|c|c|c|c|c|}
\hline & \multirow{2}{*}{$\begin{array}{c}\text { Total } \\
\text { subjects }\end{array}$} & \multicolumn{2}{|c|}{$\begin{array}{c}\text { Number/Percent } \\
\text { Reported Smoking }\end{array}$} & \multirow[b]{2}{*}{ Population Studied } & \multirow[b]{2}{*}{ Screening Tool } \\
\hline & & $n$ & $\%$ & & \\
\hline Uganda [8] & 610 & 6 & 1.0 & Urban; national referral hospital & Clinic interview \\
\hline Malawi [9] & 2,058 & 86 & 4.2 & Rural; antenatal clinics & Clinic interview/follow-up \\
\hline Benin [10] & 4,113 & 329 & 8.0 & Urban; prenatal clinics & Clinical examination/interview \\
\hline $\begin{array}{l}\text { Democratic Republic of } \\
\text { the Congo [11] }\end{array}$ & 847 & 2 & 0.2 & Urban; antenatal sites & Interview/questionnaire \\
\hline Zimbabwe [12] & 80 & 36 & 45.0 & Urban; adolescent; prenatal clinics & Review of prenatal interviews \\
\hline South Africa [13] & 636 & 290 & 45.6 & Urban/rural mix; prenatal clinics & Clinic interview \\
\hline Zambia [11] & 909 & 2 & 0.2 & Mostly urban; antenatal sites & Interview/questionnaire \\
\hline
\end{tabular}




\section{Statistical Analysis}

Analysis of variance (ANOVA) was used to examine the differences in means of continuous dependent variables (e.g., average cigarettes smoked per day and maternal weight). A chi-square procedure was used to examine the strength of the relationship between two categorical variables (e.g., women who reported smoking in pregnancy and women who did not smoke in pregnancy). Statistical significance (alpha level) was set at .05 for all analyses.

\section{Results}

From 10 prenatal care sites in Brazzaville, 3,099 women completed the screening and had complete data. The rate of cigarette smoking was low, with 5.5\% $(n=172)$ of women reporting smoking any amount during pregnancy (Table 2). Women who smoked during pregnancy had a mean of just over $1.13(s d=.4)$ cigarettes per day and a maximum of 3 cigarettes per day (Table 3$)$. Only $11 \%$ ( $n=$ 19) of smokers reported smoking 2 or more cigarettes per day during pregnancy.

The data in Table 2 categorized women into two groups: smokers $(n=172)$ and non-smokers $(n=2927)$. The mean gestational week for smokers at the current visit was 25.63 weeks ( $s d=7.17$ weeks). This did not greatly differ by group: smokers (25.63 weeks; $s d=7.17$ ) compared to nonsmokers (26.1 weeks; $s d=6.67)$. The mean age of participants was 27.22 years ( $s d=5.65$ years). The non- smokers' mean age was 27.23 (sd $=5.64$ years) and the smokers' mean age was 27.04 ( $s d=5.78$ years). Smokers weighed $56.6 \mathrm{~kg}(s d=4.44)$, compared to $57.17 \mathrm{~kg}$ ( $s d=$ 4.85) for non-smokers, which was not a statistically significant difference.

\section{Smoking and Drinking}

Among women who never smoked, 18.9\% $(n=516)$ reported prenatal alcohol use. Of the 172 women who smoked, 93\% also drank during pregnancy. Thus, smoking is an important risk marker to identify women who have a 4.9-fold increase in risk for prenatal alcohol exposure. The women reporting smoking were found to have increased alcohol use for every alcohol exposure variable. Women smoking had statistically significant increases in drinks per drinking day; number of binge episodes; drinking days per week; and drinks at any one time (Table 3). Women who smoke and drink report drinking 3 more drinks per drinking day, and having 2.2 more drinking days per week, than their non-smoking peers (Table 3). Over the course of the 40 weeks of pregnancy, the estimated prenatal alcohol exposure difference was 266 more drinks and 80 more binge episodes (four or more drinks at one time) for the average woman who smoked. This comorbid exposure has important health consequences, especially for the fetus and child, since smoking is also associated with increased risk for adverse outcomes when accompanied by prenatal alcohol exposure (Odendaal, Steyn, Elliot, \& Burd, 2009).

Table 2

Summary data on maternal age, weight and gestational age at current visit from 3,099 women attending prenatal care in Brazzaville, Congo

\begin{tabular}{|c|c|c|c|c|c|c|c|}
\hline \multirow[b]{2}{*}{ Factor } & \multicolumn{2}{|c|}{ Smokers $n=172$} & \multicolumn{2}{|c|}{ Non-Smokers $n=2,927$} & \multicolumn{2}{|c|}{ Total $N=3,099$} & \multirow[b]{2}{*}{$\boldsymbol{P}$} \\
\hline & $M$ & $S D$ & $M$ & $S D$ & $M$ & $S D$ & \\
\hline Weight (kilos) & 56.60 & 4.44 & 57.17 & 4.85 & 57.14 & 4.83 & $P=.13$ \\
\hline Gestational week at current visit & 25.63 & 7.17 & 26.10 & 6.67 & 26.07 & 6.70 & $P=.37$ \\
\hline Age (years) & 27.04 & 5.78 & 27.23 & 5.64 & 27.22 & 5.65 & $P=.67$ \\
\hline
\end{tabular}

Note. Statistical procedure used was ANOVA. $P=$ difference between smokers and non-smokers; $M=$ mean; $S D=$ standard deviation.

Table 3

Summary data on the five exposure variables from 3,099 women attending prenatal care in Brazzaville, Congo

\begin{tabular}{|c|c|c|c|c|c|c|c|c|c|}
\hline \multirow[b]{2}{*}{ Factor } & \multicolumn{2}{|c|}{$\begin{array}{c}\text { Smokers } \\
n=172\end{array}$} & \multicolumn{2}{|c|}{$\begin{array}{c}\text { Non-Smokers } \\
n=2,729\end{array}$} & \multirow{2}{*}{$\begin{array}{c}\text { Between } \\
\text { Group } \\
\text { Difference }\end{array}$} & \multirow{2}{*}{$\begin{array}{l}\text { Difference } \\
\text { Ratio }\end{array}$} & \multicolumn{2}{|c|}{$\begin{array}{c}\text { Total } \\
N=3,099\end{array}$} & \multirow[b]{2}{*}{$\boldsymbol{P}$} \\
\hline & $M$ & $S D$ & $M$ & $S D$ & & & $M$ & $S D$ & \\
\hline Average drinks per drinking day & 3.76 & 1.83 & 0.73 & 1.67 & 3.0 & 5.2 & 0.90 & 1.82 & $<.001$ \\
\hline $\begin{array}{l}\text { Average binge episodes in } \\
\text { pregnancy }\end{array}$ & 3.78 & 3.40 & 0.66 & 1.99 & 3.12 & 5.7 & 0.83 & 2.21 & $<.001$ \\
\hline Most drinks at once in pregnancy & 6.71 & 2.66 & 1.29 & 2.89 & 5.4 & 5.2 & 1.59 & 3.13 & $<.001$ \\
\hline Drinking days per week & 2.67 & 1.36 & 0.49 & 1.14 & 2.2 & 5.4 & 0.61 & 1.26 & $<.001$ \\
\hline
\end{tabular}

Note. Statistical procedure used was ANOVA. $P=$ difference between smokers and non-smokers; $M=$ mean; $S D=$ standard deviation. 
Table 4

Summary of the variable means and standard distributions by participant smoking status

\begin{tabular}{|c|c|c|c|c|}
\hline Variable & $\begin{array}{c}\text { Total Smoking (sd) } \\
n=172\end{array}$ & $\begin{array}{c}\text { At } \operatorname{Risk}^{1}(s d) \\
n=9\end{array}$ & $\begin{array}{c}\text { High Risk }^{2}(s d) \\
n=151\end{array}$ & $\begin{array}{c}\text { Total Exposed }^{3}(s d) \\
n=160^{4}\end{array}$ \\
\hline Cigarettes per day & 1.13 cigs/day (0.40) & 1.11 cigs/day (0.33) & 1.13 cigs/day (0.41) & 1.13 cigs/day (0.41) \\
\hline Drinks per drinking day & 3.76 drinks/day (1.83) & 3.33 drinks/day (1.50) & 4.06 drinks/day (1.62) & 4.02 drinks/day (1.62) \\
\hline Drinking days per week & 2.67 days/week (1.36) & 3.89 days/week (1.17) & 2.77 days/week (1.21) & 2.83 days/week (1.23) \\
\hline Binges $^{5}$ in pregnancy & 3.85 binges (3.41) & 4.11 binges (3.55) & 4.11 binges (3.39) & 4.11 binges (3.39) \\
\hline Age & 26.96 years $(5.71)$ & 29.25 years $(5.0)$ & 26.46 years $(5.57)$ & 26.60 years $(5.56)$ \\
\hline Weight & $56.60 \mathrm{~kg}(4.44)$ & 58.44 kg (3.57) & $56.23 \mathrm{~kg}(4.37)$ & $56.35 \mathrm{~kg}(4.35)$ \\
\hline Gestational week & 25.63 weeks (7.17) & 18.44 weeks (6.46) & 26.39 weeks (6.60) & 25.94 weeks (6.83) \\
\hline
\end{tabular}

Note. ${ }^{1}$ At Risk women who reported drinking during pregnancy, but quit upon recognition of pregnancy. ${ }^{2}$ High Risk women who reported drinking during pregnancy, and continued to drink. ${ }^{3}$ Total Exposed combines the At Risk and High Risk groups. ${ }^{4}$ The difference in the $n$ of the total smoking and total exposed column results from 12 women who smoked but were not included in the total exposed (which combines the At Risk and High Risk categories). ${ }^{5}$ Binges $=4$ or more drinks on any one occasion

The statistical modeling of adverse outcomes from a comprehensive review of combined exposure supports the conclusion that the combined exposure of prenatal smoking and alcohol use are not additive, but rather multiplicative, for many adverse outcomes (Odendaal et al., 2009). These findings support the need for widespread comprehensive public health intervention efforts to reduce maternal smoking and alcohol use before and during pregnancy, with an emphasis on efforts to reduce either or both of these behaviors across the childbearing years.

We then grouped study participants into two categories, based on their alcohol use status at the time of screening: (1) High Risk (women who continued drinking after pregnancy recognition); and (2) At Risk (women who did drink during pregnancy but reported quitting upon recognition of pregnancy) (Table 4). Nine smokers (5.6\%) made up the "At Risk" drinking group and each smoked an average of 1.11 ( $s d=0.33$ ) cigarettes per day (Table 4). The "High Risk" group consisted of 151 smokers (87\%) who reported using 1.13 ( $s d=0.41$ ) cigarettes per day (Table 4); these women are likely at an increased risk for a wide range of adverse outcomes (Odendaal et al., 2009).

While the sample of women who smoke was small, the 151 "High Risk" drinking women who smoke did have the highest-risk pregnancies. These women smoked the most cigarettes per day (1.13 sd $=.41)$ and had the highest number of average drinks per day $(4.06 s d=1.62)$ and highest rate of binge drinking (89\%) (Table 4). By comparison, the non-smokers had a binge drinking rate of $16.3 \%$, averaged $0.66(s d=1.99)$ binge episodes in pregnancy, and averaged 0.73 drinks per day $(s d=1.67$ ) (Table 2). At the time of the screening, the average woman in the "High Risk" smoking group was entering her third trimester, suggesting high levels of cumulative exposure to smoking and alcohol and an increased number of binge episodes during pregnancy. This would be a priority population for public health risk reduction strategies.

\section{Discussion}

In this prospective study of 3,099 pregnant women in Brazzaville, Congo, we found that one in 18 of the women (5.5\%) reported smoking during pregnancy. Increased efforts to detect maternal smoking may be important, since both exposure and the resulting adverse outcomes are potentially preventable.

Utilizing data on the number of cigarettes each participant smoked per day, we devised a formula to estimate cumulative cigarettes smoked for this population. For each study participant who reported smoking during pregnancy, we multiplied the number of cigarettes smoked per day by seven (assuming they smoke every day each week), and then multiplied that number by their gestational week. Figure 1 plots the estimated number of cumulative cigarettes smoked for each woman to her screening date $(n=172)$.

There were 79 smokers in their third trimester (28 weeks and later). In Figure 1, we labeled third-trimester data points with the number of women associated with each data point. At the most populous data point, 23 women (29.1\%) had smoked 252 cigarettes through 36 weeks of pregnancy. This is equivalent to one cigarette per day. Though this seems like a small amount of daily exposure, prolonged exposure to low levels of cigarette use still puts the pregnancy at increased risk for adverse birth outcomes, especially for women who drink alcohol during pregnancy (Odendaal et al., 2009). 


\section{Figure 1}

Graphic estimate of cumulative cigarettes smoked in pregnancy for 172 women in Brazzaville. (Third trimester data points include the number of women for each data point).

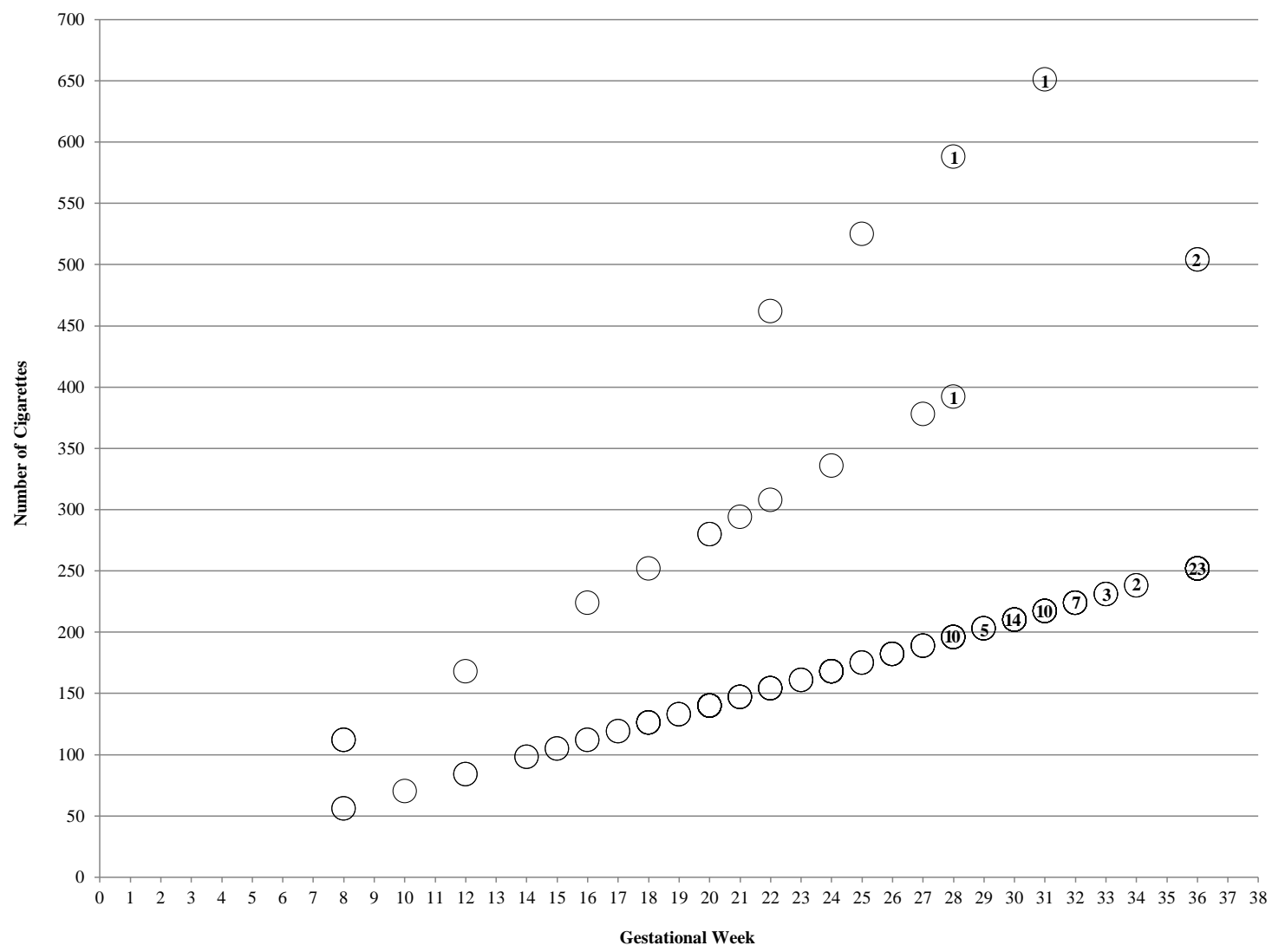

Is it plausible that low-level smoking is an important risk marker for other adverse outcomes during pregnancy? Intermittent smokers exhibit features of tobacco dependence (Rose, Dierker, \& Donny, 2010; Shiffman, Ferguson, Dunbar, \& School, 2012). Multiple reports have also demonstrated a relationship between smoking and alcohol use during pregnancy (Anderka et al., 2010; England et al., 2010; Ernster, 2000). Smoking during pregnancy is well recognized as a risk marker for fetal alcohol spectrum disorders (Burd, Blair, \& Dropps, 2012; Cannon et al., 2012; Flanagan \& Kokotailo, 1999; Kvigne, Randall, Simanton, Brenneman, \& Welty, 2012; Masho et al., 2012; Meschke et al., 2012).

In this study, $5.5 \%$ of women reported smoking. Table 3 shows the difference ratios for alcohol use between the 172 smokers and the 2,729 non-smokers in this population. On "average drinks per day," "average binges episodes in pregnancy," "most drinks at once in pregnancy," and "drinking days per week," smokers had at least a five-fold increase when compared to non-smokers. Screening for prenatal smoking in this population is important, considering that smokers have such a dramatic increase in alcohol use compared to non-smokers, and that 160 out of 172 (93\%) of the smokers in this population use alcohol (Tables 3 \& 4). In the Congo, smoking appears to be a useful screen for comorbid alcohol use. Obtaining a positive screen for prenatal smoking also provides another avenue for in-pregnancy interventions to reduce the risk of adverse pregnancy outcomes. While associations between smoking and alcohol use have been previously reported (Odendaal et al., 2009), we believe this is the first report to quantify the magnitude of risk of smoking and accompanying prenatal alcohol use in a population of pregnant women from Africa.

\section{Limitations/Opportunities}

This study had several limitations. A major limitation was that all data were self-reported and we cannot exclude the possibility that women underreport smoking rates. However, unless data are obtained to refute these findings, spending the additional funds to validate reporting accuracy with cotinine testing seems unwarranted in impoverished countries like the Congo.

The use of a prospective study design minimizes the time period of recall for exposure. The exposed data in this study asked about current use for cigarettes and alcohol during pregnancy. 
One important benefit from screening to identify women who smoke may be the opportunity to utilize office-based intervention to decrease exposure for the current pregnancy and prevent exposure in subsequent pregnancies. This could have important, low-cost, cumulative health impacts for families, and could lead to a reduction in second-hand and third-hand smoke exposure for other infants and children and improved health for the adults in the household. Early adoption of prenatal care also allows for earlier screening and a chance for many more women to have an exposure-free second and third trimester.

As the developing world is being more heavily targeted by tobacco advertisers, and the risk of smoking is increased, now may be an opportune time to implement appropriate intervention and prevention plans in the Congo (Ernster et al., 2000; Geirsson \& Tolosa, 2010; Mackay et al., 2006). By starting prevention plans early, public health authorities may achieve more success in keeping smoking rates low than if they try to reduce smoking rates after marketing campaigns have dramatically increased prevalence. There have been few prevention or intervention plans about smoking in Brazzaville or the Congo. We did not collect data that would inform us of why certain women do not smoke, or do not quit smoking during pregnancy. This information will be collected in future studies and would allow public health authorities in the Congo (and international organizations) to plan and implement an appropriate plan of action.

Maternal smoking increases risk for maternal morbidity, preterm birth, stillbirth, neonatal and infant death. These are public health outcomes of concern in the Congo, and decreasing maternal smoking may be a strategy to reduce risk for these outcomes. Further research on the health effects of smoking in the Congo will be required to identify affordable and effective interventions.

\section{References}

Anderka, M., Romitti, P. A., Sun, L., Druschel, C., Carmichael, S., Shaw, G., \& The National Birth Defects Prevention Study. (2010). Patterns of tobacco exposure before and during pregnancy. Acta Obstetricia Et Gynecologica Scandinavica, 89, 505-514.

Burd, L., Blair, J., \& Dropps, K. (2012). Prenatal alcohol exposure, blood alcohol concentrations and alcohol elimination rates for the mother, fetus and newborn. Journal of Perinatology, 32, 652-659.

Cannon, M. J., Dominique, Y., O’Leary, L. A., Sniezek, J. E., \& Floyd, R. L. (2012). Characteristics and behaviors of mothers who have a child with fetal alcohol syndrome. Neurotoxicology and Teratology, 34, 90-95.

Central Intelligence Agency. (2012). The world factbook 2012: Country comparison: Infant mortality rate. Retrieved from https:/www.cia.gov/library/publications/ the-world-factbook/geos/cf.html

Chaibva, C. N., Ehlers, V. J., \& Roos, J. H. (2011). Audits of adolescent prenatal care rendered in Bulawayo, Zimbabwe. Midwifery, 27, e201-e207. doi:10.1016/j. midw.2010.07.009
Cnattingius, S. (2004). The epidemiology of smoking during pregnancy: Smoking prevalence, maternal characteristics, and pregnancy outcomes. Nicotine Tobacco Research, 6, S125-S140.

Croxford, J., \& Viljoen, D. (1999). Alcohol consumption by pregnant women in the Western Cape. South African Journal of Sports Medicine, 89, 962-965.

Doskotch, P. (2008). Many pregnant women use tobacco in some developing countries. International Family Planning Perspectives, 34, 199.

England, L. J., Kim, S. Y., Tomar, S. L., Ray, C. S., Gupta, P. C., Eissenberg, T., ... Tolosa, J. E. (2010). Noncigarette tobacco use among women and adverse pregnancy outcomes. Acta Obstetricia Et Gynecologica Scandinavica, 89, 454-464.

Ernster, V., Kaufman, N., Nichter, M., Samet, J., \& Yoon, S.-Y. (2000). Women and tobacco: Moving from policy to action. Bulletin of the World Health Organization, 78, 891-901.

Flanagan, P., \& Kokotailo, P. (1999). Adolescent pregnancy and substance use. Clinics in Perinatology, 26, 185-200.

Fourn, L., Ducic, S., \& Seguin, L. (1999). Smoking and intrauterine growth retardation in Republic of Benin. Journal of Epidemiology \& Community Health, 53, 432433.

Geirsson, R. T., \& Tolosa, J. E. (2010). Smoking, tobacco exposure and pregnancy. Acta Obstetricia Et Gynecologica Scandinavica, 89, 414-415.

Jagoe, K., Edwards, R., Mugusi, F., Whiting, D., \& Unwin, N. (2002). Tobacco smoking in Tanzania, East Africa: Population based smoking prevalence using expired alveolar carbon monoxide as a validation tool. Tobacco Control, 11, 210-214.

Kadir, M. M., McClure, E. M., Goudar, S. S., Garces, A. L., Moore, J., Onyamboko, M., . . . The Global Network Tobacco Study Group. (2010). Exposure of pregnant women to indoor air pollution: A study from nine low and middle income countries. Acta Obstetricia Et Gynecologica Scandinavica, 89, 540-548.

Kvigne, V. L., Randall, B., Simanton, E. G., Brenneman, G., \& Welty, T. K. (2012). Blood alcohol levels for American Indian mothers and newborns. Pediatrics, 130, e1015-e1018. doi:10.1542/peds.2011-1400

Mackay, J. Eriksen, M., \& Shafey, O. (2006). The tobacco atlas (2nd ed.). Atlanta, GA, United States: American Cancer Society.

Masho, S. W., Bishop, D. L., Keyser-Marcus, L., Varner, S. B., White, S., \& Svikis, D. (2013). Least explored factors associated with prenatal smoking. Maternal and Child Health Journal, 17, 1167-1174. doi:10.1007/s10995012-1103-y

McDermott, J., Steketee, R., Larsen, S., \& Wirima, J. (1993). Syphilis-associated perinatal and infant mortality in rural Malawi. Bulletin of the World Health Organization, 71, 773-780.

Meschke, L. L., Holl, J., \& Messelt, S. (2013). Older not wiser: Risk of prenatal use by maternal age. Maternal and Child Health Journal, 17, 147-155. doi:10.1007/s10995-012-0953-7

Namagembe, I., Jackson, L. W., Zullo, M. D., Frank, S. H., Byamugisha, J. K., \& Sethi, A. K. (2010). Consumption 
of alcoholic beverages among pregnant urban Ugandan women. Maternal and Child Health Journal, 14, 492500.

Odendaal, H. J., Steyn, D. W., Elliot, A., \& Burd. L. (2009). Combined effects of cigarette smoking and alcohol consumption on perinatal outcome. Gynecologic and Obstetric Investigation, 67, 1-8.

Partnership for Maternal, Newborn \& Child Health. (2012). Born too soon: The global action report on preterm birth. Retrieved from http://www.who.int/pmnch/media/ news/2012/preterm_birth_report/en/index4.html

Population Reference Bureau. (2012). World population data sheet. Birth rate (annual number of births per 1,000 total population). Retrieved from http://www.prb.org/ DataFinder/Topic/Rankings.aspx?ind=3

Rose, J. S., Dierker, L. C., \& Donny, E. (2010). Nicotine dependence symptoms among recent onset adolescent smokers. Drug and Alcohol Dependence, 106, 126-132.

Shiffman, S., Ferguson, S. G., Dunbar, M. S., \& School, S. M. (2012). Tobacco dependence among intermittent smokers. Nicotine Tobacco Research, 14, 1372-1381.

United Nations Department of Economic and Social Affairs/Population Division. (2010). World population prospects. Volume II: Demographic profiles. Geneva, Switzerland: United Nations. Retrieved from http://esa.un.org/wpp/Documentation/pdf/WPP2010_Vol ume-II_Demographic-Profiles.pdf

U.S. Department of State. (2012). Background notes: Republic of the Congo. Retrieved from http://www.state.gov/r/pa/ei/bgn/2825.htm.

World Health Organization. (2010). Trends in maternal mortality 1990-2008. Geneva, Switzerland: WHO Press.

World Health Organization. (2011). World health statistics. Geneva, Switzerland: WHO Press. Retrieved from http://www.who.int/whosis/whostat/EN_WHS2011_Full. pdf 